\title{
On the pressure drop in Plate Heat Exchangers used as desorbers in absorption chillers
}

\author{
N. García-Hernando ${ }^{\text {a,* }}$, J.A. Almendros-Ibáñez ${ }^{\text {b,c }}$, G. Ruiz ${ }^{\text {d }}$, M. de Vega ${ }^{\text {a }}$ \\ ${ }^{a}$ Energy System Engineering (ISE), Departamento de Ingeniería Térmica y de Fluidos, Universidad Carlos III de Madrid, Avda. Universidad, 30,28911 Leganés, Madrid, Spain \\ ${ }^{\mathrm{b}}$ Escuela de Ingenieros Industriales de Albacete, Departamento de Mecánica Aplicada e Ingeniería de Proyectos, Universidad de Castilla La Mancha, Campus Universitario s/n, \\ 02071 Albacete, Spain \\ ${ }^{\mathrm{c}}$ Renewable Energy Research Institute, c/de la Investigación s/n, 02071 Albacete, Spain \\ ${ }^{\mathrm{d}}$ Energy Efficiency and Renewables Department, Técnicas Reunidas S.A., C/Arapiles No. 13, 10ª 28015 Madrid, Spain
}

\begin{abstract}
A B S T R A C T
The influence of the pressure drop in Plate Heat Exchangers (PHE) in the boiling temperature of $\mathrm{LiBr}_{2} \mathrm{O}$ and $\mathrm{NH}_{3} \quad \mathrm{H}_{2} \mathrm{O}$ solutions is studied. For the $\mathrm{NH}_{3} \quad \mathrm{H}_{2} \mathrm{O}$ solution, the pressure drop temperature saturation relationship estates that high pressure drops can be allowed in the solution with negligible changes in the saturation temperature, and in the PHE performance. Besides, in the case of the $\mathrm{LiBr} \mathrm{H}_{2} \mathrm{O}$ solution, as the working pressure is usually very low, the analysis of the pressure drop must be taken as a main limiting parameter for the use of Plate Heat Exchangers as vapour generators. In this case, the pressure drop may considerably change the boiling temperature of the solution entering the heat exchanger and therefore a higher heating fluid temperature may be required. A guideline to design these systems is proposed.
\end{abstract}

\section{Introduction}

Absorption chillers, compared to mechanical refrigeration sys tems, are generally larger in size and that limits to a great extend their use in low and medium power applications. For instance a typical value for the volume to refrigeration power ratio in single effect absorption chillers is in the order of $0.04 \mathrm{~m}^{3} / \mathrm{kW}$ (without considering the volume occupied by the cooling system) for refrig eration capacities between 10 and $30 \mathrm{~kW}$, whereas the mechanical compressor systems can have a ratio equal to $0.02 \mathrm{~m}^{3} / \mathrm{kW}$ for the same range of refrigeration capacities. This is a clear inconvenient for the generalization of the absorption technology use, limiting its benefits in the contribution to the reduction in $\mathrm{CO}_{2}$ emissions, specially in the case of the $\mathrm{LiBr} \mathrm{H}_{2} \mathrm{O}$ solution as this system can be fed with low heat temperature sources as solar panels $[1,2]$.

In order to avoid this large volume concern, attempts have been made to scale down their size. One way of reducing the size of these systems is the use of compact heat exchangers. Plate Heat Exchangers (PHE) have been used not only for the solution heat re cover [3] but also for the absorber [4,5] or the generator [6]. The precautions when using this last possibility relative to the solution

\footnotetext{
* Corresponding author. Tel.: +34 916248 885; fax: +34 916249430 .

E-mail address: ngarcia@ing.uc3m.es (N. García-Hernando).
}

pressure drop and its influence on the boiling temperature are studied here.

In the present work, we are interested in the relationship between pressure drop and saturation temperature, and its effect on the temperature profile in the PHE generator of an absorption chiller. This new consideration must be taken into account as a rel atively important pressure drop may occur in a PHE used as the generator of an absorption system. This was not the case until now as in pool boiling the pressure drop is not appreciable. Even if some authors have experimentally measured these high pressure drop values [6], to the authors knowledge, the effect on the heat exchanger design and performance have never been studied. Both aspects are treated here.

\section{Description of the absorption cycle, without pressure drop in the generator}

In most of the cases, absorption systems are theoretically stud ied considering a negligible pressure drop in the heat exchangers [7]. The resulting ideal thermodynamic cycle can be easily solved in this case and as a result, knowing the evaporation and the con densation temperatures, the inlet and outlet temperatures of the flowing fluids in the different heat exchangers can be calculated. In the present study, a $\mathrm{LiBr} \mathrm{H}_{2} \mathrm{O}$ and a $\mathrm{NH}_{3} \quad \mathrm{H}_{2} \mathrm{O}$ ideal cycles have been taken as reference cases, with an evaporation temperature 


\begin{tabular}{|c|c|c|c|}
\hline ch & chilled water & \multicolumn{2}{|c|}{ Greek symbols } \\
\hline $\mathrm{CW}$ & cold water & $\rho$ & density \\
\hline DP & pressure drop & $v_{m}$ & specific volume of the vapour liquid mixture \\
\hline$f$ & friction factor & & \\
\hline$G$ & fluid mass flux & \multicolumn{2}{|c|}{ Subscripts } \\
\hline$\dot{m}$ & mass flow rate & $i$ & inlet \\
\hline Pc & condensation pressure & $l$ & liquid \\
\hline$T$ & temperature & $m$ & mean \\
\hline$V$ & mean velocity & 0 & outlet \\
\hline$x$ & mass fraction & REF & refrigerant \\
\hline$y$ & vapour mass fraction & DIS & solution \\
\hline
\end{tabular}

equal to $7{ }^{\circ} \mathrm{C}$ and a condensation temperature equal to $40^{\circ} \mathrm{C}$. The procedure for the calculation is similar to that presented in de Vega et al. [8], and the corresponding equipment is depicted in Fig. 1. In the case of the $\mathrm{NH}_{3} \mathrm{H}_{2} \mathrm{O}$, the vapour separator should also include a rectifier for the final distillation of $\mathrm{NH}_{3}$.

The resulting calculated temperatures of the solution at the in let $\left(7: t_{\text {INLET }}\right)$ and at the outlet $\left(8: t_{\text {OUTLET }}\right)$ of the desorber, and the corresponding initial boiling temperatures at the given inlet con centration of the solution ( $\left.t_{\text {BolLING }}\right)$ are presented in Figs. 2 and 3 for different vapour mass fractions of the refrigerant separated during the desorption. In these figures, the mass fraction $y$ is the ratio between the refrigerant mass flux entering the condenser and the solution mass flux entering the desorber. In terms of the inlet and outlet concentrations, it can be expressed as:

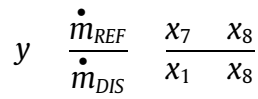

$y \frac{\dot{m}_{R E F}}{\dot{m}_{D I S}} \frac{x_{8} \quad x_{7}}{x_{8}}$

where $x_{7}$ and $x_{8}$ are the $\mathrm{NH}_{3}(1)$ or the $\mathrm{LiBr}(2)$ mass fractions.

These temperatures in the ideal cycle increase as the solution and the generated vapour are circulating through the heat exchan

DESORBER

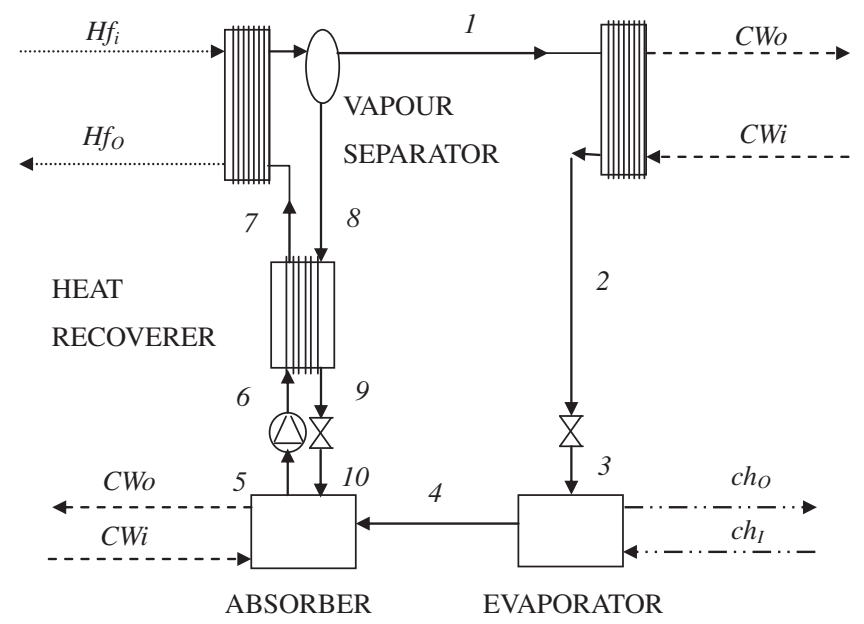

Fig. 1. Components of the absorption chiller. ger during the desorption. In fact, for a given operating pressure of the generator, the initial temperature for the boiling condition is the same (for given evaporator and condenser temperatures), inde pendent of the vapour mass fraction of the refrigerant separated $y$ as shown in Figs. 2 and 3. In these figures, as well as in the rest of figures of the paper, the temperature profiles are just estimated, as in Gabrielii and Vamling [9]: the interesting point is that in all the cases, for the solution, $t_{\text {INLET }}<t_{\text {BOILING }}<t_{\text {OUTLET }}$. This allows in princi ple the use of a counter current flow PHE configuration for the heating fluid.

Without considering pressure drop, the maximum temperature in the cycle is the one at the exit of the generator and therefore the temperature of the heating fluid has to be in accordance with this value. In the case of the $\mathrm{NH}_{3} \mathrm{H}_{2} \mathrm{O}$ this temperature can be larger than $100{ }^{\circ} \mathrm{C}$ for a mass vapour fraction separated of $16.6 \%$ and it could be around $95{ }^{\circ} \mathrm{C}$ for the $\mathrm{LiBr} \mathrm{H}_{2} \mathrm{O}$ case with a mass vapour fraction separated in the order of $7 \%$, which allows the use of solar collectors as the heating source.

\section{Boiling temperature and pressure drop in PHE}

The assumption of a negligible pressure drop is consistent with the use of pool boiling for the vapour generation. Nevertheless,

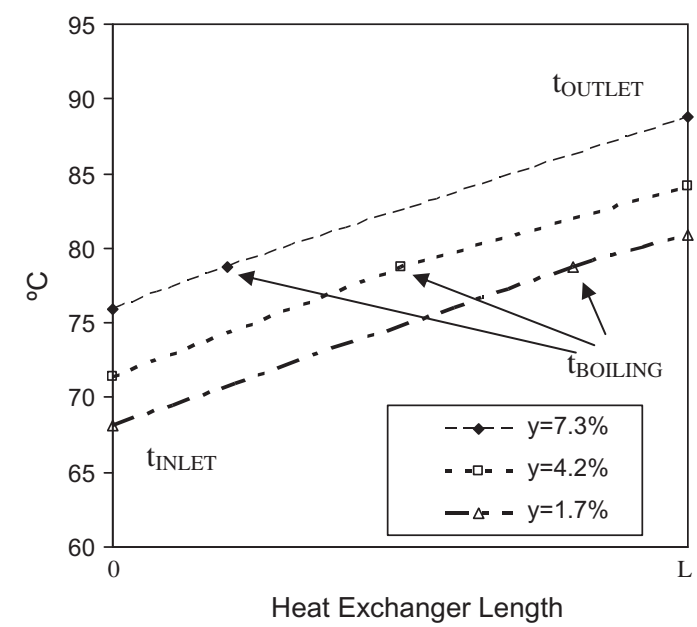

Fig. 2. Estimated temperature profiles along the desorber of a $\mathrm{NH}_{3}-\mathrm{H}_{2} \mathrm{O}$ cycle without pressure drop, for different vapour mass fractions of refrigerant: evaporation temperature $=7{ }^{\circ} \mathrm{C}$; condensation temperature $=40{ }^{\circ} \mathrm{C} \quad\left(\mathrm{xin}_{\mathrm{NH} 3}=52.4 \%\right.$; xout $_{\mathrm{NH} 3}=42.9 \%, 46.9 \%$ and $48.9 \%$ ). 


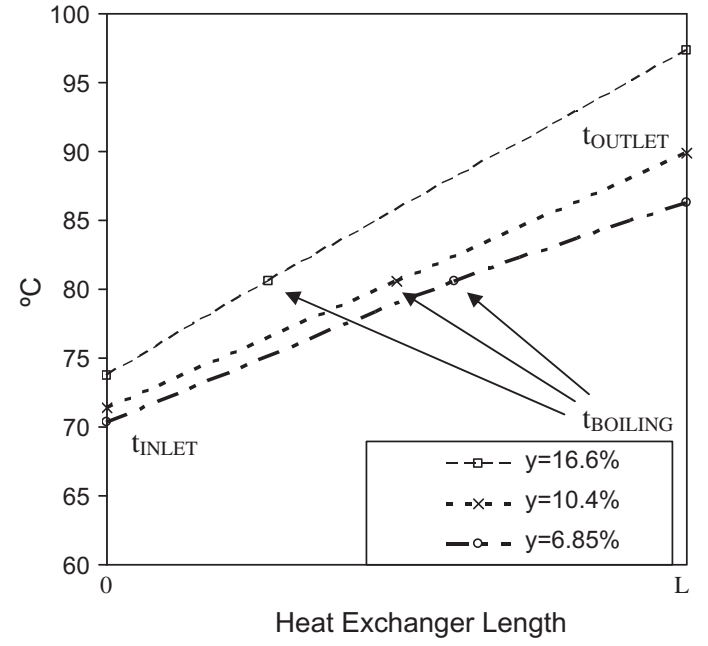

Fig. 3. Estimated temperature profiles along the desorber of a $\mathrm{LiBr}-\mathrm{H}_{2} \mathrm{O}$ cycle without pressure drop, for different vapour mass fractions of refrigerant: evaporation temperature $=7^{\circ} \mathrm{C}$; condensation temperature $=40{ }^{\circ} \mathrm{C} \quad\left(\operatorname{xin}_{\mathrm{LiBr}}=56.9 \%\right.$; xout $_{\mathrm{LiBr}}=61.4 \%, 59.4 \%$ and $57.9 \%$ ).

when considering the possibility of using a PHE as desorber, an estimation of the expected pressure drop must be performed, and the possible changes in the temperature needed for the sepa ration of the refrigerant should be calculated. This temperature is higher than the one in the ideal case, as it will correspond to the saturation temperature at the generator pressure (that is, the con denser operating pressure) plus the pressure drop. Figs. 4 and 5 show the initial boiling temperatures that are necessary to make the solution boil for different solution concentrations, as a function of different possible values of the pressure drop. The outlet operat ing pressures are the same as in the ideal case: $7.4 \mathrm{kPa}$ for the $\mathrm{LiBr}$ $\mathrm{H}_{2} \mathrm{O}$ and $1.6 \mathrm{MPa}$ for the $\mathrm{NH}_{3} \mathrm{H}_{2} \mathrm{O}$ solution.

The sensitivity of the boiling temperature on the generator pressure drop is plotted in Figs. 4 and 5, showing how it is more important in the $\mathrm{LiBr} \mathrm{H}_{2} \mathrm{O}$ case, due to the low working pressure

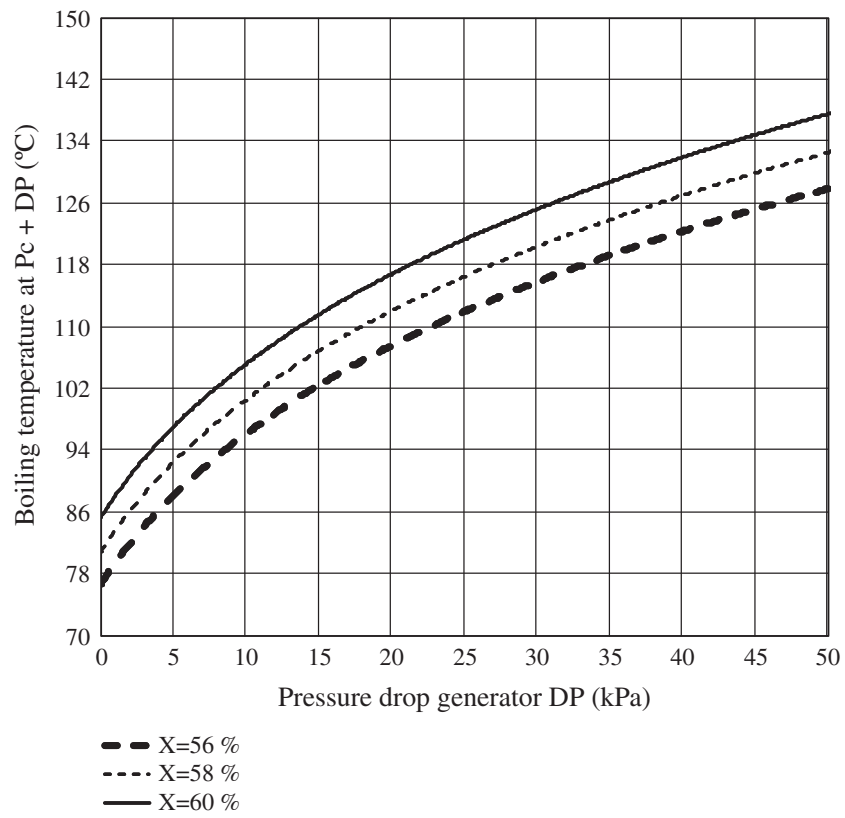

Fig. 4. Boiling temperature for a $\mathrm{LiBr}-\mathrm{H}_{2} \mathrm{O}$ solution for a generator operating at $\mathrm{Pc}=7.4 \mathrm{kPa}$ (condensation temperature of $40^{\circ} \mathrm{C}$ ) considering different values of the pressure drop DP and concentrations at the desorber inlet.

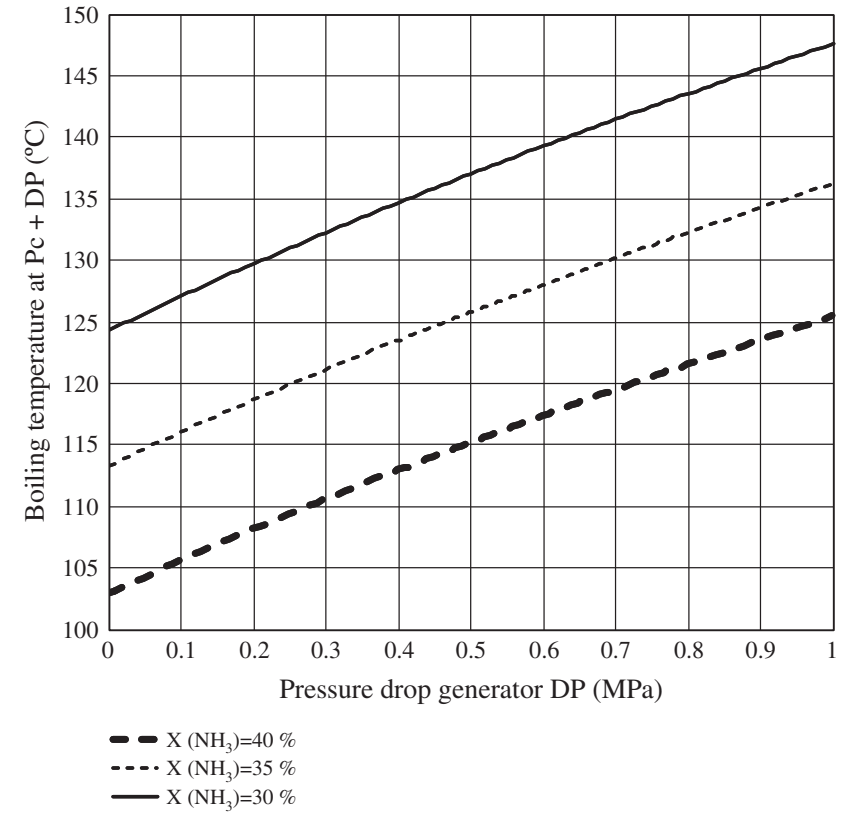

Fig. 5. Boiling temperature for a $\mathrm{NH}_{3}-\mathrm{H}_{2} \mathrm{O}$ solution for a generator operating at $\mathrm{PC}=1.6 \mathrm{MPa}$ (Condensation temperature of $40^{\circ} \mathrm{C}$ ) considering different values of the pressure drop DP.

of the systems that use this solution. For pressure drops less than $10 \mathrm{kPa}$, an increase of $15^{\circ} \mathrm{C}$ in the boiling temperature is expected. This is not the case of the $\mathrm{NH}_{3} \mathrm{H}_{2} \mathrm{O}$ solution, where a $10 \%$ pressure drop implies a temperature increase of only $3^{\circ} \mathrm{C}$ for the boiling process to take place.

We will try in the following to calculate what could be a reason able value of the pressure drop in a conventional PHE used as gen erator in order to predict the real initial boiling temperature.

\subsection{Lithium bromide water generator}

We have considered an application of a chiller with a $5 \mathrm{~kW}$ of refrigeration capacity. We propose a design for the desorber using a PHE. We will focus first in the $\mathrm{LiBr} \mathrm{H}_{2} \mathrm{O}$ case. Initially, the design will be based on the conventional use of the inlet and outlet tem peratures of the solution of Fig. 3 as design temperatures. For the present case, we have selected oil as the heating fluid as in Marcos et al. [6]. Therefore the design working conditions are: inlet solu tion temperature, $75^{\circ} \mathrm{C}$, outlet solution temperature $88^{\circ} \mathrm{C}$ which correspond to a mass vapour fraction of refrigerant separated equal to $6.6 \%$. According to Hewitt [10] the selected PHE for these design conditions is an Alfa Laval AC30 model, with 15 plates. The design aims at having a small sized heat exchanger (according to a small refrigeration capacity $5 \mathrm{~kW}$ ) with the minimum number of plates for the desorber capacity required $(6.4 \mathrm{~kW})$. The size of the heat exchanger (325 mm (high), $93 \mathrm{~mm}$ (width) and $28.5 \mathrm{~mm}$ (depth)) is smaller than the size required for a similar application using a pool boiling configuration.

To the authors knowledge there is no correlation available in the literature for the calculation of the pressure drop in channels or tubes for the desorption of the refrigerant in $\mathrm{LiBr} \mathrm{H}_{2} \mathrm{O}$ or $\mathrm{NH}_{3} \quad \mathrm{H}_{2} \mathrm{O}$ solutions. Accordingly, a literature review has been done, relating to the process of boiling of different refrigerant mixtures, in order to estimate the order of magnitude of the pressure drop presumably encountered in a PHE when used in the desorption process in an absorber chiller [11 14].

The result of the literature review allows us to estimate this pressure drop considering mainly the influence of the frictional factor as: 
$D P \quad \frac{1}{2} f \frac{L}{v_{m} D_{h}} V^{2}$

where $L$ is the channel length, $D_{h}$ is the hydraulic diameter (which is twice the channel gap of the PHE considered), $v_{m}$ is the specific vol ume of the vapour liquid mixture, $V$ the mean velocity and $f$ is the friction factor. According to Hsieh and Lin [14], the following corre lation can be used for the phase change in mixtures:

f $15250 \operatorname{Re}_{e q}^{1.25}$

where $\operatorname{Re}_{e q}$ is the equivalent Reynolds number, defined as:

$\operatorname{Re}_{e q} \frac{G_{e q} D_{h}}{\mu_{l}}$

and

$G_{e q} \quad G\left[1 \quad y_{m}+y_{m}\left(\frac{\rho_{l}}{\rho_{g}}\right)^{1 / 2}\right]$

$G_{e q}$ is an equivalent mass flux which is a function of the fluid mass flux $(G)$, mean quality $y_{m}$ and density at the saturated conditions.

It is worth noting that the employed correlation in [14] has been obtained for $\mathrm{R} 410 \mathrm{~A}$, and not for a $\mathrm{LiBr} \mathrm{H}_{2} \mathrm{O}$ solution. Never theless, when the results are compared to the experimental values of Marcos et al. [6], a reasonable agreement is found and a differ ence lower than $15 \%$ is obtained.

The designed heat exchanger will work with a pressure drop in the solution size of $40.9 \mathrm{kPa}$ (according to Eq. (3)), with a heating fluid inlet and outlet temperatures of $132^{\circ} \mathrm{C}$ and $119{ }^{\circ} \mathrm{C}$. It is inter esting to note that the use of a small sized PHE may have a nega tive consequence on the possible use of a low temperature heating source, as the heat transfer surface lowers.

\subsubsection{Temperature along the PHE}

The desorber will now be studied taking into account the pres sure drop and its influence on the temperature profile along the PHE. For the present case, a pressure drop of $40.9 \mathrm{kPa}$ will require a higher boiling temperature, i.e. $122^{\circ} \mathrm{C}$ according to Fig. 4.

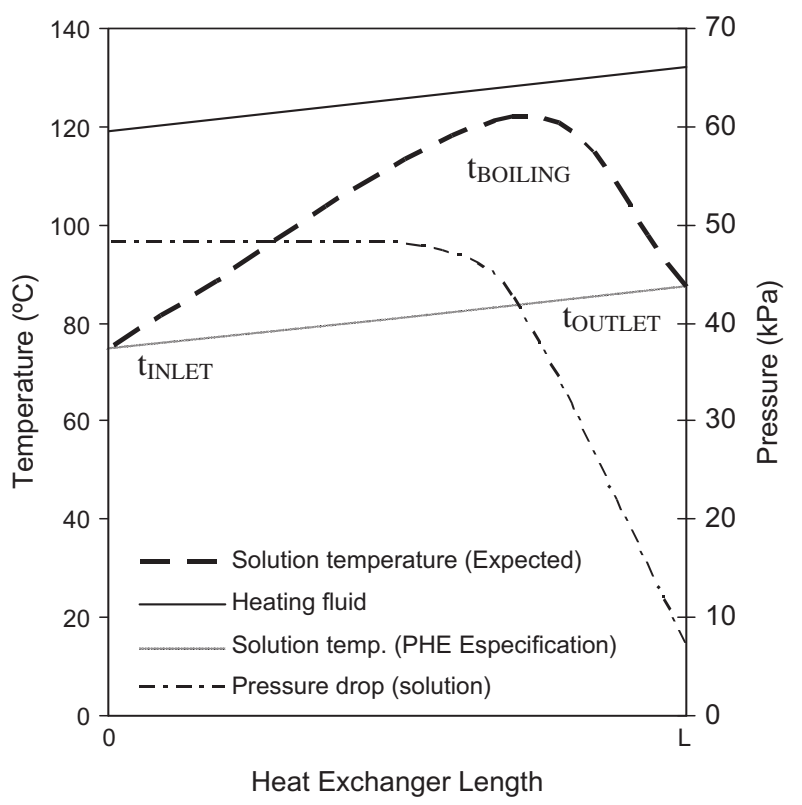

Fig. 6. Expected temperature profiles and pressure along the desorber of a $\mathrm{LiBr}-$ $\mathrm{H}_{2} \mathrm{O}$ cycle with pressure drop: evaporation temperature $=7^{\circ} \mathrm{C}$; condensation temperature $=40{ }^{\circ} \mathrm{C}\left(\operatorname{xin}_{\mathrm{LiBr}}=56.9 \%\right.$; xout $\left._{\mathrm{LiBr}}=60.9 \%\right)$.
Therefore, for the design conditions (i.e., outlet temperature of the solution and calculated pressure drop), the new expected tem perature profile is shown in Fig. 6. In this figure, the expected pres sure drop is also shown: we have considered that during the single phase heat exchange, the pressure drop is considerably lower than in the two phase flow case $[11,15,16]$.

The temperature profile in the solution side along the desorber changes drastically when compared to the ideal case, and

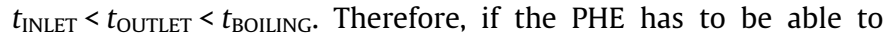
transfer the designed $6.5 \mathrm{~kW}$ and to separate the required mass of refrigerant, a heating temperature higher than the one initially considered will be needed.

One way to avoid this performance problem is to design the PHE in order to limit the allowable pressure drop that will make $t_{\mathrm{BO}}$ ING $=t_{\text {OUTLET }}$. Fig. 7 shows the limiting pressure drop allowable in the generator for different operating conditions as a function of the mass vapour fraction separated. If the expected pressure drop is higher than the one represented in the Fig. 7, the temperature profile along the PHE will give a maximum not at the exit, but somewhere inside it, and therefore a design procedure for the counter cross flow configuration must be considered with care (this is explained in the next section). In addition, the temperature of the external heating fluid should be higher than in the ideal case.

\subsection{Ammonia water generator}

A similar procedure employed in the $\mathrm{NH}_{3} \quad \mathrm{H}_{2} \mathrm{O}$ case will provide a temperature profile in the desorber as shown in Fig. 8, for a pres sure drop of $16 \mathrm{kPa}$.

In the case of the $\mathrm{NH}_{3} \mathrm{H}_{2} \mathrm{O}$ system, the temperature profile in the PHE is similar to the ideal case, without pressure drop, and the sequence $t_{\text {INLET }}<t_{\text {BOILING }}<t_{\text {OUTLET }}$ still remains.

For the $\mathrm{NH}_{3} \mathrm{H}_{2} \mathrm{O}$ solution, the pressure drop temperature satu ration relationship (Fig. 5) established that high pressure drops can be allowed in the solution with negligible changes in the temper ature profile (Fig. 8), i.e. this parameter is not a limiting factor for the use of PHE in the desorber.

Besides, in the case of the $\mathrm{LiBr} \mathrm{H}_{2} \mathrm{O}$ solution (Fig. 4), as the working pressure is very low, the analysis of the pressure drop must be taken as a main limiting parameter for the use of PHE as an adequate heat exchanger in the vapour generator. In this case, the pressure drop may considerably change the boiling tempera ture of the solution entering the heat exchanger (Fig. 6).

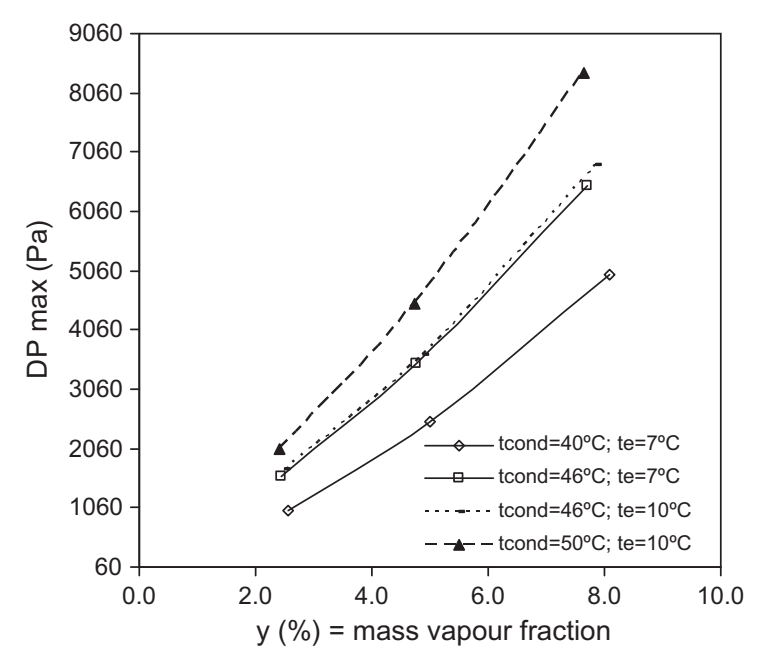

Fig. 7. Pressure drop that makes the initial boiling temperature equal to the outlet temperature in the desorber for $\mathrm{LiBr}-\mathrm{H}_{2} \mathrm{O}$. 


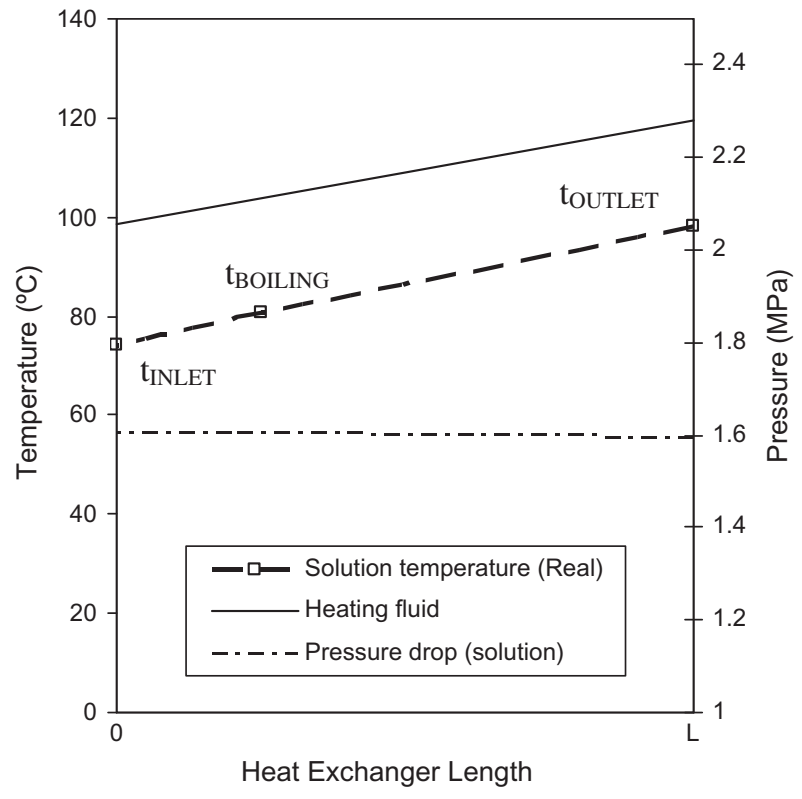

Fig. 8. Expected temperature profiles and pressure along the desorber of a $\mathrm{NH}_{3}-$ $\mathrm{H}_{2} \mathrm{O}$ cycle with pressure drop: evaporation temperature $=7^{\circ} \mathrm{C}$; condensation temperature $=40^{\circ} \mathrm{C}\left(\mathrm{xin}_{\mathrm{NH} 3}=52.4 \%\right.$; xout $\left._{\mathrm{NH} 3}=42.9 \%\right)$.

\subsection{Experimental considerations}

As already stated, to the authors' knowledge, there is not en ough literature information. In Marcos et al. [6], a double effect $\mathrm{LiBr} \mathrm{H}_{2} \mathrm{O}$ absorption chiller has been tested with an indirectly heated PHE used as high temperature desorber. In this application, the operating pressure of the PHE is $130 \mathrm{kPa}$. As in a previous sec tion, we can calculate the change in boiling temperature, for differ ent pressure drops (Fig. 9).

Comparing Fig. 9 with Fig. 4, it can be seen that, as the PHE is working at a higher pressure, the change in boiling temperature

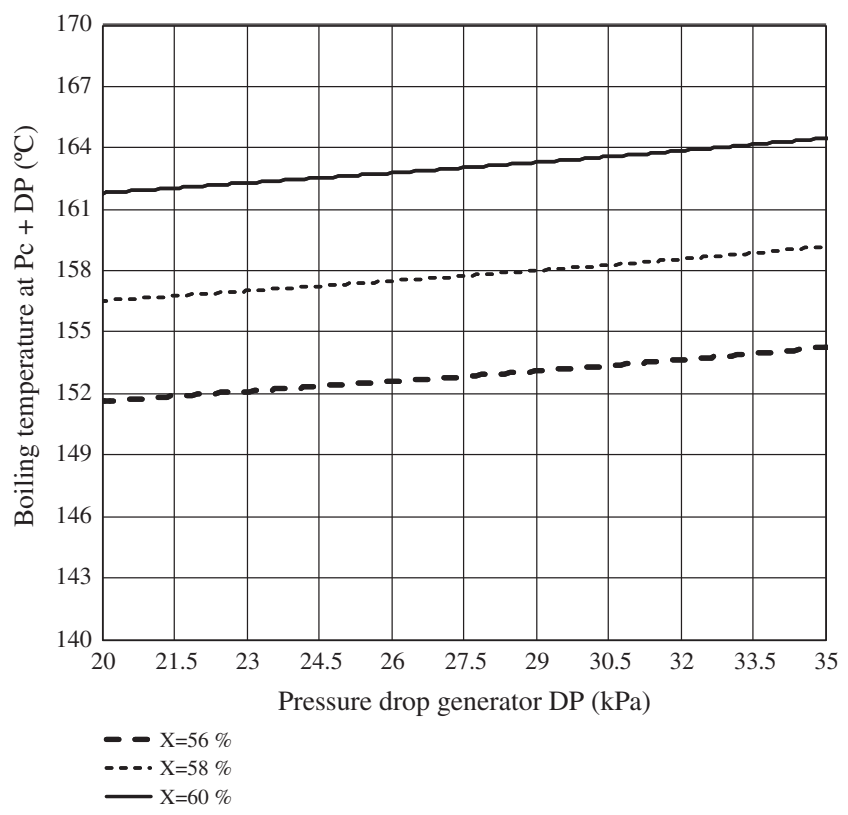

Fig. 9. Boiling temperature for a $\mathrm{LiBr}-\mathrm{H}_{2} \mathrm{O}$ solution for a PHE generator operating at $130 \mathrm{kPa}$ considering different values of the pressure drop DP and concentrations at the desorber inlet.

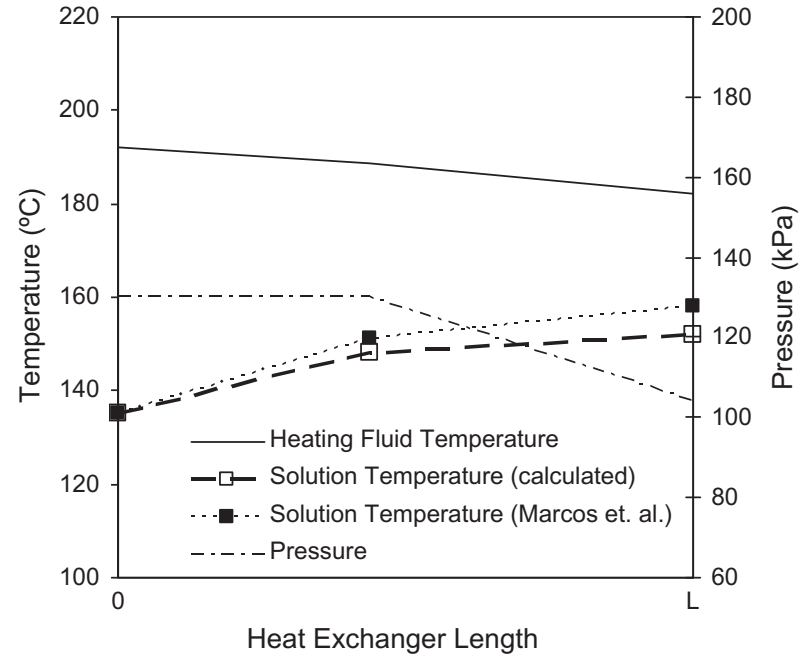

Fig. 10. Expected and measured temperature profiles and pressure along the desorber of a $\mathrm{LiBr}-\mathrm{H}_{2} \mathrm{O}$ PHE with pressure drop: pressure inlet: $130 \mathrm{kPa}$; $\left(\operatorname{xin}_{\mathrm{LiBr}}=56 \% ;\right.$ xout $\left._{\mathrm{LiBr}}=57.5 \%\right)$.

is around $5{ }^{\circ} \mathrm{C}$ for a pressure drop of $25 \mathrm{kPa}$. This is in agreement with the experimental results of Marcos et al. [6]. According to these authors, the employed PHE has 30 chevron type plates, $112 \mathrm{~mm}$ width and $250 \mathrm{~mm}$ length with a plate thickness of $0.5 \mathrm{~mm}$ and a distance between plates of $2.6 \mathrm{~mm}$. The inlet and outlet temperatures of the solution are measured. The inlet and outlet temperatures of the heating fluid (oil) are also measured. Following a similar procedure as the one presented in Section 3.1., we have compared these measurements with the expected values of the solution along the PHE, taking into account the pres sure drop. The results are presented in Fig. 10.

In this case, as the operating pressure in the PHE is the one cor responding to the high pressure desorber of a double effect cycle $(130 \mathrm{kPa})$ it is considerably higher than in the generator of a single effect chiller $(7.5 \mathrm{kPa})$. Therefore, the pressure drop influence is not a limiting parameter for the operation.

\section{Plate Heat Exchangers used as generators}

It seems that the reduction in size with the use of PHE as desorber may have negative consequences. Nevertheless, we sug gest that the use of this kind of heat exchangers may be useful pro vided some care is taken in the design.

In order to reduce the pressure drop, one solution may be the use of a higher number of plates until the solution mass flow rate (and its velocity) will be low enough to reduce the pressure drop as required in Fig. 7. However, this option will lead simultaneously to a lower mass flow rate per channel in the hot side: while the high boiling heat transfer coefficient of the solution side will not consid erably change at a lower mass flow rate, in the hot side, on the con trary, the lower the mass flow rate, the lower heat transfer coefficient and the higher heat transfer area (owing to a high num ber of plates) will not compensate the overall heat transfer coeffi cient decrease. Therefore with this configuration, in order to transfer the heat required between the hot and the solution side, the hot temperature maybe too high (which will limit the use of low temperature solar collectors, as heating sources). Therefore, a better option will be to increase the number of plates as required by the pressure drop limit, but minimizing the decrease in the heat transfer coefficient in the hot fluid side. The proposed design is then a multipass PHE. 


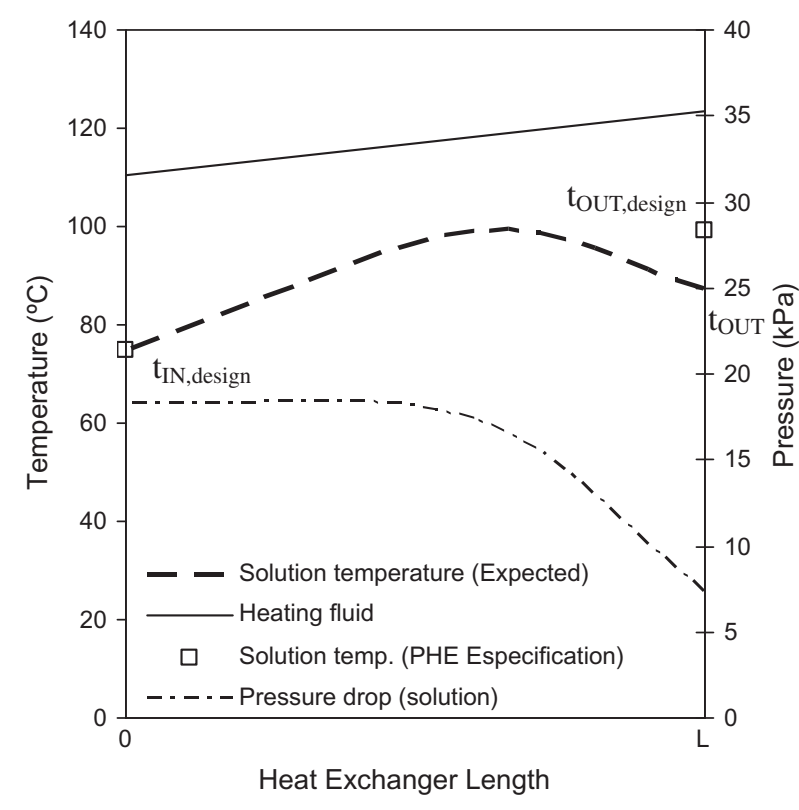

Fig. 11. Temperatures along the desorber of a $\mathrm{LiBr}-\mathrm{H}_{2} \mathrm{O}$ cycle with pressure drop: evaporation temperature $=7^{\circ} \mathrm{C}$; condensation temperature $=40^{\circ} \mathrm{C}\left(\mathrm{xin}_{\mathrm{LiBr}}=56.9 \%\right.$; xout $_{\mathrm{LiBr}}=60.9 \%$ ).

If the limit in the pressure drop in Fig. 7 is too restrictive, an other possibility for the design is to take the initial boiling temper ature that results from the pressure drop in the generator as design temperature for the solution. In this case the temperature lift needed will be higher but the refrigerant separation will be guaranteed.

For our case, taking into account the first consideration, the sug gested heat exchanger will be a multipass PHE, with two passes for the heating fluid and 1 pass for the solution [17]. With the same model (AC30) and this 21 configuration a 53 plate PHE will pro vide both, the heat transfer needed and the required quantity of refrigerant, and the final size will still be small $(325 \times 93 \times$ $85.5 \mathrm{~mm}$ and $5.6 \mathrm{~kg}$ ), According with the second condition design (the design temperature is not the outlet solution temperature but the real boiling temperature), the heat transfer and the refrig erant required in the cycle will be guaranteed.

The results in Fig. 11 show that the increase in the heat transfer surface compensates for the decrease in the heat transfer coeffi cient and therefore, which is also important and beneficial, the in let hot temperature is lower. As a conclusion, the product of the overall heat transfer coefficient and the heat exchanger surface, UA is higher than in a 11 pass PHE and therefore the logarithmic mean temperature difference can be lower, for a given heating capacity. For our case, with the multipass configuration and 53 plates to reach a solution temperature of $99.3^{\circ} \mathrm{C}$ (which corre sponds to the boiling temperature) and a refrigerant mass fraction of $6.5 \%$, the heating fluid will be at $123.4{ }^{\circ} \mathrm{C}$ less than the initial $132{ }^{\circ} \mathrm{C}$ of the one pass configuration With this configuration, the pressure drop is lower than $11 \mathrm{kPa}$.

\section{Conclusions}

The influence of the pressure drop in the desorption of the refrigerant in $\mathrm{NH}_{3} \mathrm{H}_{2} \mathrm{O}$ and $\mathrm{LiBr} \mathrm{H}_{2} \mathrm{O}$ solutions has been analyzed.
For the $\mathrm{NH}_{3}$ case, as the working pressure is relatively high, the dif ferences found in the desorption temperature without and with pressure drop during the desorption, are almost negligible. This is not the case for the $\mathrm{LiBr} \mathrm{H}_{2} \mathrm{O}$ solution as changes in desorption temperatures as high as $30^{\circ} \mathrm{C}$ for pressure drops as low as $20 \mathrm{kPa}$ can occur. Therefore, the pressure drop in the desorber is the key factor in the design of $\mathrm{LiBr} \mathrm{H}_{2} \mathrm{O}$ absorption chillers operating with PHE. The design temperature, which defines the thermal level of the hot fluid, may not be the outlet temperature of the solution, but the initial boiling temperature which is a direct function of the pressure drop. A limiting value of this pressure drop that gives the possibility of a counter current flow with the maximum tem perature localized at the exit of the heat exchanger is also proposed as an alternative design guideline.

\section{Acknowledgment}

This work has been partly supported by the "Ayuda a grupos" of CAM under the project numbers CCG07 UC3M/AMB 3412 and CCG08 UC3M/AMB 4227.

\section{References}

[1] Kim DS, Infante Ferreira CA. Air-cooled LiBr-water absorption chillers for solar air conditioning in extremely hot weathers. Energy Convers Manage 2009;50:1018-25.

[2] Mateus T, Oliveira AC. Energy and economic analysis of an integrated solar absorption cooling and heating system in different building types and climates. Appl Energy 2009;86:949-57.

[3] Jeong JY, Hong HK, Kim SK, Kang YT. Impact of plate design on the performance of welded type plate heat exchangers for sorption cycles. Int J Refrig 2009;32:705-11.

[4] Vallès M, Bourouis M, Boer D, Coronas A. Absorption of organic fluid mixtures in plate heat exchangers. Int J Therm Sci 2003;42:85-94.

[5] Cerezo J, Bourouis M, Vallès M, Coronas A, Best R. Experimental study of an ammonia-water bubble absorber using a plate heat exchanger for absorption refrigeration machines. Appl Therm Eng 2009;29:1005-11.

[6] Marcos JD, Izquierdo M, Lizarte R, Palacios E, Infante Ferreira CA. Experimental boiling heat transfer coefficients in the high temperature generator of a double effect absorption machine for the lithium bromide/water mixture. Int J Refrig 2009;32:627-37.

[7] Kang YT, Kunugi Y, Kashiwagi T. Review of advanced absorption cycles: performance improvement and temperature lift enhancement. Int J Refrig 2000;23:388-401.

[8] de Vega M, Almendros-Ibanez JA, Ruiz G. Performance of a LiBr-water absorption chiller operating with plate heat exchangers. Energy Convers Manage 2006;47:3393-407.

[9] Gabrielii C, Vamlig L. Changes in optimal distribution of heat exchanger area between the evaporator and suction gas heat exchanger when replacing R22 with R407C. Int J Refrig 1998;21:440-51.

[10] Hewitt GF, editor. Thermal and hydraulic design of heat exchangers. Heat exchanger design handbook, Part 3. New York: Begel House Inc.; 1998.

[11] Wellsandt S, Vamling L. Heat transfer and pressure drop in a plate-type evaporator. Int J Refrig 2003;26:180-8.

[12] Kreissig G, Müller-Steinhagen HM. Frictional pressure drop for gas/liquid twophase flow in plate heat exchangers. Heat Transfer Engineering 1992;13:42-52.

[13] Djordjevic E, Kabelac S. Flow boiling of R134a and ammonia in a plate heat exchanger. Int J Heat Mass Transfer 2008;51:6235-42.

[14] Hsieh YY, Lin TF. Saturated flow boiling heat transfer and pressure drop of refrigerant R-410A in a vertical plate heat exchanger. Int J Heat Mass Transfer 2002;45:1033-44.

[15] Manglik RM. Plate heat exchangers for process industry applications: enhanced thermal-hydraulic characteristics of chevron plates, process, enhanced and multiphase heat transfer. Begell House: New York; 1996 [p. 267-76].

[16] Morales-Ruiz S, Rigola J, Pérez-Segarra CD, García-Valladares O. Numerical analysis of two-phase flow in condensers and evaporators with special emphasis on single-phase/two-phase transition zones. Appl Therm Eng 2009;29:1032-42.

[17] Miura RY, Galeazzo FCC, Tadini CC, Gut JAW. The effect of flow arrangement on the pressure drop of plate heat exchangers. Chem Eng Sci 2008;63:5386-93. 